\title{
Maxillary sinus textiloma: a case report
}

\author{
Yoann Pons*, Thomas Schouman
}

\begin{abstract}
Introduction: Textilomas have been reported in many locations. We report the first case of textiloma located in the maxillary sinus that mimicked a sinus cyst recurrence on computed tomography images.

Case presentation: A 60-year-old Caucasian man was referred for persistent infection of the right maxillary sinus. A maxillary sinus benign cyst had been removed three months before. Computed tomography showed a sinus opacity evoking a cyst recurrence. A new operation was planned to remove the cyst by a Caldwell-Luc approach. After excision of very thick fibrous tissue, a compress was discovered in the maxillary sinus. The patient did not present with any sinus infection after the operation.

Conclusion: The surgeon should always take into account the possibility of textilomas in a patient with a history of sinus surgery.
\end{abstract}

\section{Introduction}

Textiloma can be defined as a mass within the body composed of cotton matrix, which usually refers to a retained surgical sponge or compress, surrounded by a foreign-body reaction [1].

Most cases of textiloma reported in the literature have been connected to abdominal, orthopaedic and cardiothoracic surgery [1-3]. At the head level, few intra-cranial cases have been reported $[4,5]$. No case, to date, has been reported at the face level. The authors reported the first case of textiloma located in the maxillary sinus.

\section{Case presentation}

A 60-year-old Caucasian man was referred to us for persistent infection of the right maxillary sinus. He was operated on three months ago for a benign cyst. A Caldwell-Luc operation was performed. Since this operation, the patient complained of having recurrent sinusalgia with purulent rhinorrhea. Computed tomography (CT) showed a sinus opacity evocating a cyst recurrence (Figure 1). A new surgery was planned to remove the cyst by a new Caldwell-Luc operation. After excision of very thick fibrous tissue, a compress was discovered in the maxillary sinus (Figure 2). The patient did not present any sinus infection after the operation.

\footnotetext{
* Correspondence: pons.yoann@gmail.com
Maxillofacial Surgery Department, AP-HP - Pitié-Salpêtrière University

* Correspondence: pons.yoann@gmail.com
Maxillofacial Surgery Department, AP-HP - Pitié-Salpêtrière University

Hospital, University of Paris 6, France
}

\section{Conclusions}

The main complication of a maxillary sinus textiloma is a persistent infection. In this case, the sinusitis was limited (that is, no orbital or meningeal complications occurred).

The erroneous diagnosis of a mass provoked by the presence of a textiloma was frequently reported in the literature in other regions [1-5]. In this case, both the radiologist and the surgeon had suggested the diagnosis of cyst recurrence, given the CT-scan examination. However, at a second viewing of the images, some radiologic signs of textiloma were noticed: the mass was heterogeneous with a rectilinear alternation of thin bands (solid-band and air-band densities) that corresponded to the meshing of the compress. Moreover, foreign bodies of the maxillary sinus are a common cause of persistent infection. The diagnosis was finally corrected by the surgery, which definitively cured the patient.

The suspicion of textiloma should be raised when a patient with a history of previous maxillary sinus surgery presents with a history of chronic sinus infection associated with a sinus mass on CT images, even though textiloma is unlikely to be found in such a small cavity.

\section{Consent}

Written informed consent was obtained from the patient for publication of this case report and accompanying 


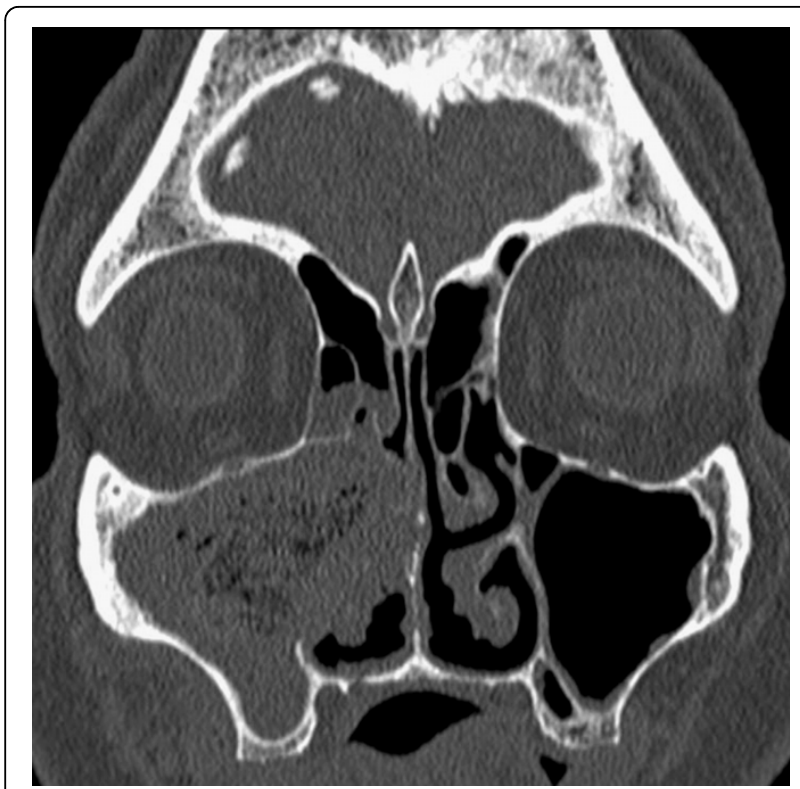

Figure $1 \mathrm{CT}$ scan imaging showing the textiloma located in the maxillary sinus and mimicking a cyst recurrence.

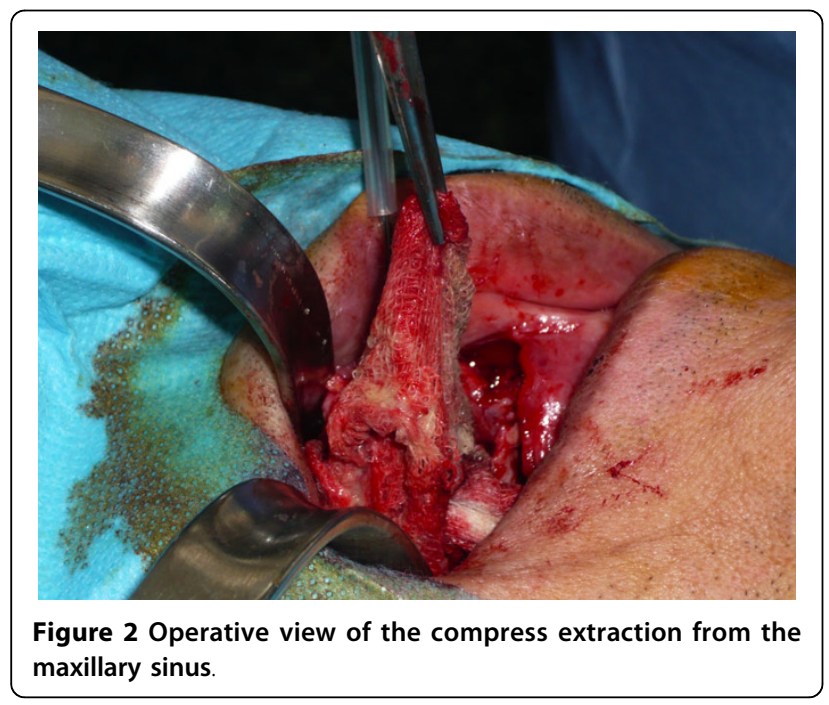

images. A copy of the written consent is available for review by the Editor-in-Chief of this journal.

\section{Authors' contributions}

YP redacted the manuscript. TS supervised the manuscript. Both authors read and approved the final manuscript.

\section{Authors' information}

The authors are two medical doctors. Yoann Pons is a head and neck surgeon.

Thomas Schouman is a maxillofacial surgeon.

\section{Competing interests}

The authors declare that they have no competing interests.
Received: 6 January 2010 Accepted: 24 August 2010

Published: 24 August 2010

\section{References}

1. Nobre LF, Marchiori E, May F, Carrão AD Jr, Zanetti G, Machado DM: Thoracic textilomas after myocardial revascularisation: typical CT findings. Br J Radiol 2010, 83:4-7.

2. Poyanli A, Salmaslioğlu A, Terzibașioğlu E, Toker A, Tanju S, Aydin K: An unsusual pure cystic posterior mediastinal mass: a textiloma. Clin Radiol 2008, 63:863-868.

3. Yamamura N, Nakajima K, Takahashi T, Uemura M, Nishitani A, Souma Y, Nishida T: Intra-abdominal textiloma: a retained surgical sponge mimicking a gastric gastrointestinal stromal tumor: a case report. Surg Today 2008, 38:552-554.

4. Razzag AA, Chishti MK: Foreign body granuloma after craniotomy for tumor: a diagnostic dilemma. Br J Neurosurg 2000, 14:591-592.

5. Feldman RP, Marcovici A, Suarez M, Goodrich JT: Foreign body granuloma mimicking intracranial meningioma: case report and review of the literature. Neurosurgery 1999, 44:855-858.

doi:10.1186/1752-1947-4-288

Cite this article as: Pons and Schouman: Maxillary sinus textiloma: a case report. Journal of Medical Case Reports 2010 4:288.

\section{Submit your next manuscript to BioMed Central and take full advantage of:}

- Convenient online submission

- Thorough peer review

- No space constraints or color figure charges

- Immediate publication on acceptance

- Inclusion in PubMed, CAS, Scopus and Google Scholar

- Research which is freely available for redistribution 